\title{
Human genetics in Johannesburg, South Africa: Past, present and future
}

\author{
J G R Kromberg, BA (Soc Work), MA, PhD; A Krause, MB BCh, PhD \\ Jennifer Kromberg is an honorary Associate Professor in the Division of Human Genetics, Faculty of Health Sciences, University of the Witwatersrand \\ and National Health Laboratory Service (NHLS), Johannesburg, South Africa. Amanda Krause is a medical geneticist and heads the Clinical \\ Section of the Division of Human Genetics, Faculty of Health Sciences, University of the Witwatersrand and NHLS, Johannesburg, South Africa.
}

Corresponding author: J G R Kromberg (jennifer.kromberg@nhls.ac.za)

Genetic services were set up in Johannesburg, South Africa, in the late 1960s, but only became widespread and formalised after the first Professor of Human Genetics, Trefor Jenkins, was installed at the University of the Witwatersrand in 1974. The first services involved chromosome studies, and these developed into genetic counselling services. Prenatal diagnosis began to be offered, particularly for older women at risk for chromosome abnormalities in the fetus, and those at risk for neural tube defects. Genetic screening was then initiated for the Jewish community because of their high carrier rate for Tay-Sachs disease. Educational courses in human genetics were offered at Wits Medical School, and medical as well as other health professionals began to be trained. Research, supported by national and international bodies, was integral in the activities of the Department (now Division) of Human Genetics and focused on genetic conditions affecting the generally understudied black community. In the late 1980s the first training programme for genetic counsellors was started at MSc level, and postgraduate scientists at $\mathrm{MSc}$ and $\mathrm{PhD}$ levels studied in and qualified through the Department. At the same time molecular genetic laboratories were set up. In the late 1990s training for medical geneticists was initiated. Extensive high-quality genetic services developed over the four decades were comparable to those of most other departments in developed countries.

S Afr Med J 2013;103(12 Suppl 1):957-961. DOI:10.7196/SAMJ.7220

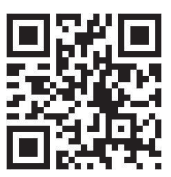

\section{Background}

The decade of the 1950s was a dramatic one for the field of human genetics. Watson and Crick constructed a DNA model in 1953, and the correct number of chromosomes in humans (46) was finally identified. ${ }^{[1]}$ The development of genetic services in South Africa started soon thereafter. Initially, cytogenetics laboratories were established and chromosome studies were offered (first by Drs S Klempman and E Wilton). Informal genetic counselling services were initiated in Johannesburg and Cape Town in the early 1960s, and the teaching of human and medical genetics to medical students was recommended (for a detailed review of this early history, see Jenkin $\left.{ }^{[2]}\right)$. Professor Jenkins took up a post as a pathologist/ haematologist at the SAIMR in 1965 and started to focus on human and population genetics. Further development took place in 1971, when the Department of Health (DoH) and Welfare appointed a Director of Genetic Services to set up community-orientated genetic services. However, service development was expedited once the first two academic chairs of Human Genetics were established, in 1972 in

It was through the initiative of Professor Trefor Jenkins, spread over nearly four decades, that genetic services were developed in Johannesburg and its environs, genetic laboratories set up, genetic counselling clinics established, appropriate educational programmes for medical and lay people introduced, and research projects relevant to local genetic diseases developed. His department was established at and supported by the South African Institute for Medical Research (SAIMR) (now the National Health Laboratory Service (NHLS)) and as such had a strong emphasis on research, in collaboration with the University of the Witwatersrand.
Cape Town (for a review on the activities of the Division of Human Genetics, University of Cape Town, see Beighton et al..$\left.^{(3)}\right)$ and in 1974 in Johannesburg.

Professor Jenkins held the chair of Human Genetics from 1974 until his retirement in 1998, the following incumbent being Professor Denis Viljoen. During his time in the chair Professor Viljoen succeeded in increasing staff numbers, obtaining four new medical geneticist and eight new genetic counsellor posts, setting up an active clinical section in the Department, and growing the laboratories. He also initiated the training of sub-specialist medical geneticists (in the process training the first black African medical geneticist) and later the training of specialists in the field. His research interest focused on fetal alcohol syndrome, and he gained funding from the National Institutes of Health (NIH) in the USA for several associated projects across the country. These showed high rates in various areas, ${ }^{[4]}$ and he set about organising widespread appropriate community education and prevention programmes. After he retired in 2008, Professor Arnold Christianson was appointed Head of Department. Professor Christianson participated, together with Professor B Model (UK), in a project with the March of Dimes Birth Defects Foundation and the World Health Organization (WHO) on the global impact of birth defects ${ }^{[5]}$ and in a local primary healthcare project focusing on genetics education (Medical Genetics Education Project (MGEP)). He also took part in an international CAPABILITY (Capability Building for the Transfer of Genetic Knowledge and Prevention, an international collaborative network) project to investigate the issues of transfer of knowledge from developed to developing countries, and undertook a local study to assess the viability and logistics of providing a medical genetic service in rural Sekhukuniland. ${ }^{[6]}$ Further, he collaborated with countries in the European Union to set up a project to assess genetic testing and services in developing countries, and the South African study was recently completed. ${ }^{7}$ 
Unfortunately during this period the NHLS withdrew some of its support for the genetic service, by not replacing staff who resigned and not providing new posts. This has had serious implications. In 2008 there were 72 staff members in the Division of Human Genetics, whereas in 2013 there are only 41 , so that the range of laboratory tests and the provision of genetic counselling clinics had to be restricted, student and staff training had to be reduced, job prospects were poor, the service could no longer be as effective and productive as it previously was, and access to it became limited.

This article focuses on the development of departmental activities at the Department (now Division) of Human Genetics, University of the Witwatersrand and SAIMR (now NHLS), where Trefor Jenkins was the inaugural Professor, but comments are made on the other departments providing genetic services across the country, where appropriate.

\section{Genetic counselling services}

One of the first services to be developed, in 1969, was that associated with prenatal genetic diagnosis ${ }^{[8,9]}$ In 1970, a Durban couple came to Johannesburg for genetic counselling. Having had one infant with Tay-Sachs disease (TSD), they requested prenatal diagnostic testing so that they could have options for their next pregnancy. Their request stimulated the development of a TSD prenatal diagnosis programme, as well as initiation of a support group for affected families, an education programme in the Jewish community, and subsequently screening of that community for TSD.$^{[10]}$ Simultaneously a prenatal diagnosis programme was being set up to diagnose chromosome disorders (particularly trisomies) in older pregnant women and families with a history of such disorders. A couple of years later, evidence showed that alpha-fetoprotein was raised in the amniotic fluid when the infant had a neural tube defect, and prenatal diagnosis testing was initiated for these conditions too. Subsequently a molecular laboratory was set up and the first molecular prenatal diagnosis for sickle cell anaemia was performed. ${ }^{[1]}$ The development of these programmes and a 10-year review of the field in Johannesburg, describing a large series of patients (4 554), were reported by Kromberg et al. ${ }^{[12]}$ in 1989. This report showed a five-fold increase in demand over 10 years (1976 - 1985), with a correct diagnosis made in $99 \%$ of cases and a low post-amniocentesis spontaneous abortion rate of only $0.7 \%$.

Genetic counselling clinics were formalised and expanded after Professor Jenkins attended the International Congress of Human Genetics in Vienna in 1972. There he learned more about the clinics that were being initiated elsewhere in the world. In Johannesburg the first clinic was set up at the local children's hospital and staffed by himself, two medically trained cytogeneticists and a medical social worker; initially a child psychiatrist was also present as an observer, and taught the staff about their counselling roles during post-session discussions. ${ }^{\left[{ }^{[3]}\right]} \mathrm{A}$ decade or so later, data were collected and analysed on the patients using this clinic. ${ }^{[14]}$ They were found to be mainly women of child-bearing age, from the higher socioeconomic groups, referred by obstetricians or general practitioners; the reasons for referral were similar to those reported in London clinics. ${ }^{[15]}$ However, more recent data show a different picture, and most of the users of the clinics are now from the lower socioeconomic groups, with a range of genetic conditions which reflect more appropriately the population distribution of ethnic groups and their associated genetic disorders (e.g. albinism in black patients and cystic fibrosis in white patients), as well as conditions such as breast cancer for which the genetic aetiology is becoming better understood. ${ }^{[16]}$

In 1987 a new clinic was opened at Baragwanath Hospital (now Chris Hani Baragwanath Academic Hospital, $\mathrm{CHBAH}$ ), and this led to a much better utilisation of genetic counselling services by the black population, ${ }^{[17]}$ as well as new insights into how they perceived genetic disorders and genetic services ${ }^{[18]}$ and what their psychosocial needs were. Genetic counselling is currently offered at weekly paediatric and antenatal clinics at the three major Johannesburg hospitals (Charlotte Maxeke Johannesburg Academic Hospital, CHBAH and Rahima Moosa Hospital), as well as at specialist clinics for cancer genetics, neuromuscular conditions, haemophilia, and cardiac and metabolic conditions.

\section{Ethical issues}

Genetic services have been shown to be cost-effective and worthwhile, even in developing countries. About $90 \%$ of the 7.6 million babies with severe genetic conditions or malformations worldwide were born in low- or middle-income countries like South Africa. ${ }^{[19]}$ Furthermore, haemoglobinopathies alone comprise a health burden similar in scale to that of communicable and other major diseases, particularly in sub-Saharan Africa. ${ }^{[20]}$ Many inherited disorders can now be prevented and the burden of genetic diseases ameliorated with appropriate programmes. The $\mathrm{WHO}^{[21]}$ recommended that these services should be promoted and offered as an integral part of basic healthcare. It is therefore unethical not to provide them as part of a comprehensive healthcare programme.

Professor Jenkins had a longstanding interest in the ethical issues raised by the provision of genetic services, and in 1994 he was invited, as the South African representative, to participate in an international survey of medical geneticists in 36 countries on the common ethical issues arising from the practice of medical genetics. ${ }^{[22,23]}$ The fundamental ethical principles that apply include informed consent, voluntariness and confidentiality, as well as respect for autonomy, equity and privacy. After the survey several guidelines were highlighted: genetic information should only be supplied by those aware of the ethical issues involved; patients must be fully informed of the limitations of genetic tests and receive supportive genetic counselling; and children should not be tested unless there is some clear benefit for them. Other ethical issues raised included equal access to services, the provision of high-quality services, the offering of options and freedom of choice, and the use of nondirective counselling methods by well-trained counsellors, respectful of human diversity and individual differences.

\section{Development of laboratories}

The development of the cytogenetics laboratory in Johannesburg preceded the introduction of the Department of Human Genetics by several years, but this laboratory was absorbed into the Department as the latter developed. The function of the laboratory was mainly to perform chromosome studies, initially on blood samples, then on amniotic fluid samples for prenatal diagnosis and on cord blood to confirm the diagnosis in abortuses, and later on blood or skin samples from stillborn infants for diagnostic purposes. The laboratory was developed and achieved an international reputation under the leadership of Professor Renee Bernstein. At this time the DoH covered the costs of many preventive (such as prenatal diagnosis testing) and diagnostic cytogenetic tests and much useful research was undertaken, including several $\mathrm{PhD}$ projects.

Later, a serogenetics and biochemical laboratory was established to undertake serogenetic testing in populations for research purposes, then biochemical testing for diagnostic purposes (for conditions such as TSD and galactosaemia), and later DNA fingerprinting for cases of disputed paternity. This laboratory has developed quantitative fluorescent-polymerase chain reaction (QF-PCR)-based aneuploidy screening for quick molecular testing of cells from amniotic fluid samples for prenatal diagnosis of chromosome anomalies. 
The next laboratory to be set up was the molecular genetics laboratory, which was initially involved in research on the globin genes, haemoglobinopathies, the Y chromosome, mitochondrial DNA, and the genes for albinism and cystic fibrosis. This laboratory, however, has since included diagnostic work and undertakes testing to confirm diagnoses such as the muscular dystrophies, haemophilia and Huntington's disease, as well as predictive and carrier testing for these and many other genetic conditions. The staff of the laboratory currently performs $75 \%$ of the molecular genetic tests in South Africa. ${ }^{[7]}$ The full range of molecular genetic tests available in the public domain is listed in the Diagnostic Genetic Tests booklet. ${ }^{[2]}$ Also, more recently research has been expanded to cover complex genetic conditions, inherited cancers and epigenetics.

The most recent laboratory (Human Diversity) to be introduced, in the 1990s, stimulated by the original serogenetic work of Professor Jenkins, was set up to study population genetics at the molecular level. This laboratory has been very productive in studying the origins of the peoples of southern Africa, including the Khoisan peoples and some populations from neighbouring countries, such as Namibia and Madagascar, and it also offers ancestry testing for individuals wanting to investigate their origins.

\section{Research}

Research was established early on in the history of the Department. Trefor Jenkins was personally involved in many evolutionary studies, involving fieldwork in remote areas, and he wrote: 'I feel privileged to have been a researcher in the field of human genetics during the exciting times when genetic traits were being discovered and employed to improve our understanding of human evolution' (T Jenkins, 'Black Eve and the roots of our humanity' - unpublished lecture, 2008). Other research topics included specifically South African subjects, such as reconstructing the history of preliterate peoples of the subcontinent employing blood groups and protein characteristics, oculocutaneous albinism in the black population, TSD in Jewish people, pentosuria, cystic fibrosis, Fanconi's anaemia, fragile $\mathrm{X}$ syndrome, the $\mathrm{Y}$ chromosome, mitochondrial DNA, haemoglobin variation (haemoglobinopathies) and disorders in the black and Indian populations, keratolytic winter erythema, lipoid proteinosis, intellectual disability, fetal alcohol syndrome, and other rarer conditions. Many of the staff in the Department completed MSc and $\mathrm{PhD}$ degrees on their research projects, as well as publishing their findings in a wide range of academic journals.

Funding for these projects was granted by the major funding bodies, such as the South African Medical Research Council (MRC) and the National Research Foundation. Professor Jenkins was also awarded a MRC Unit from 1977 to 1993, so research funding for certain major projects was forthcoming for three periods of 5 years each. The University, the SAIMR and later the Research Trust of the NHLS, and latterly the National Department of Science and Technology, have also provided financial support for the research in the Department/ Division. Staff of the Division have received research funding from various international bodies, such as the NIH, the Centers for Disease Control, the March of Dimes, the Foggarty Foundation, the Mellon Foundation and US Aid (USA), the Wellcome Trust (UK), the WHO, the European Union and the Genographic Project of the National Geographic Society. Further funding was raised for the newly established Sydney Brenner Institute for Molecular Biosciences through staff of the Division, in conjunction with the University. Altogether this funding has resulted in a huge output of publications including journal articles, chapters in books, and books.

\section{Department of Health policies and support}

In 1977 the Minister of Health announced that genetic services were an integral part of the health system financed by the State, under the Health Act (Act 63 of 1977). Laboratory services were then expanded, demand for prenatal genetic diagnosis testing increased rapidly, ${ }^{[12]}$ and community screening for conditions such as TSD increased. ${ }^{[10}$ The DoH provided funding for several of these screening tests, since such testing could lead to the prevention of genetic disorders in families at risk. The State also introduced community education and training programmes and circulated supporting material (reviewed by $\mathrm{Opt}^{\prime} \mathrm{Hof}^{(25)}$. At the same time the academic centres in Johannesburg and Cape Town developed, with increased staffing, and the selection and training of appropriate health professionals and research-related activities increased. Genetic services were set up at the universities of Stellenbosch (in the 1970s), Pretoria (in the late 1980s, although this department was closed in 2001), and the Free State (in the early 1990s), while a paediatrician became very active in initiating appropriate clinical services in Durban.

The Policy Guidelines for the Management and Prevention of Genetic Disorders, Birth Defects and Disabilities were approved by all stakeholders and published by the $\mathrm{DoH}$ in $2001 .{ }^{[26]}$ To meet the needs of the South African population, an additional 70 medical geneticists, 300 genetic counsellors and 300 laboratory scientists would be required. The number of posts supported by the NHLS and provincial governments increased slightly in the late 1990s and early 2000s. However, a debate regarding whether genetic services were a function of the National $\mathrm{DoH}$ and/or co-ordinated by them or a function of the NHLS (as had been the case historically in Gauteng and elsewhere), or delegated to the nine provincial health departments, arose and has continued, leading to the slowing down and stifling of the established services and preventing development of new services right across the country (with the exception of KwaZulu-Natal, where one new provincial genetic counselling post has recently been created).

\section{Human resources and training}

Initially medical genetics was recognised as a sub-specialty, and in 1999 nine medical geneticists (with fellowships in paediatrics or medicine and experience in the field of human genetics) were registered with the Health Professions Council of South Africa (HPCSA) through a grandfather clause, and were working in cities across the country. Subsequently nine more medical specialists (mostly paediatricians) undertook the newly introduced 2-year medical genetics training and were registered as medical geneticists. In 2007, Medical Genetics became a primary specialty in medicine. Specialist training (over 4 years) involved completing a postgraduate MMed degree and Fellowship of the College of Medical Genetics (by completing two sets of examinations administered through the College). Currently this course is offered at the University of the Witwatersrand and at three other universities. The first two specialists graduated in 2012 and another two in 2013. In 2012 there were fifteen medical geneticists registered with the HPCSA, but only eight were in full-time academic practice (and seven registrars were in training, though two have since departed). This number means that there is one medical geneticist to every 4450000 of the population, compared with estimates of 1 per 3700000 for other developing countries and 1 per 222000 in Western developed nations in 1995. ${ }^{[27]}$

Genetic counselling in South Africa is a recognised and registered health profession, with formal training at postgraduate Master's level 
(requiring 2 years of full-time formal teaching and clinical training, a research project and a 2-year internship) and registration with the HPCSA. The development of the profession was encouraged by Professor Jenkins, and the first MSc (Genetic Counselling) course became available at the University of the Witwatersrand in the late 1980s ${ }^{[16]}$ A similar course was started in 2003 at the University of Cape Town (for a review of this history, see Greenberg et al. ${ }^{[28]}$ ). According to the HPCSA (unpublished data, 2009), there were 15 registered genetic counsellors in the country in 2008. Several were in full-time genetic counselling posts in Johannesburg, but a few were in part-time provincial or university posts, with non-governmental organisations, in private laboratories elsewhere, or in private practice. At present there are only four in full-time posts.

Medical scientists and medical technologists are trained in human genetics in the Division in Johannesburg. ${ }^{[7]}$ Many have been trained over the years and registered with the HPCSA; some continued to $\mathrm{MSc}$ and $\mathrm{PhD}$ degrees.

Informal ad hoc genetics training of various health professionals, particularly nurses, has been offered by academic professionals in the Division since the early 1980s. However, since about 2003, the Southern African Inherited Disorders Association (initially with funding from the March of Dimes, USA), based at the University of the Witwatersrand, has supported and provided medical genetics education for selected nurses and doctors working in primary healthcare. This MGEP, involving distance learning as well as tutorials, was approved later and then financed by the $\mathrm{DoH}$, and at present it is offered in several provinces.

\section{Genetic services}

The services initiated by Professor Jenkins and his staff grew, and currently key genetic services, similar to those offered elsewhere in developed countries, are available in Johannesburg. ${ }^{[7]}$ These services include prenatal genetic diagnosis, genetic screening, diagnostic, predictive and carrier testing, and genetic counselling services. Most genetic services are provided in the tertiary level public healthcare domain $(88 \%)$, while the remainder are provided in private healthcare settings in Johannesburg. ${ }^{[16]} \mathrm{A}$ regular annual outreach clinic is offered in Port Elizabeth and East London by staff of the Division; the clinic previously offered in Polokwane has had to be cancelled due to staff constraints. No genetic services are available in the rural areas, apart from the few outreach clinics provided by the academic centres, but referrals to tertiary care level can be made from the secondary and primary levels.

The laboratories of the Division of Human Genetics in Johannesburg provide some genetic testing services, mainly for sickle cell anaemia and chromosomal analysis, for patients in other African countries such as the Central African Republic, Uganda, Kenya, Zimbabwe, Botswana and Namibia, where the necessary expertise is generally unavailable.

\section{Professional and lay societies}

The Southern African Society of Human Genetics was founded in 1986, and Professor Jenkins was the first Chairman. The aims of the society were to advance the discipline by facilitating contact between human geneticists as well as between human geneticists and workers in related fields. Concerned genetic scientists need to engage in discussion on the ways in which the public and politicians can be better informed about how genetic research and services can improve the life of the country's various communities (this was stated by Professor Jenkins in $1990^{[2]}$ and still applies today). Biennial human genetics congresses were organised. The last one, held in Cape Town in 2011, was held in conjunction with the new African Society of
Human Genetics and attracted many African as well as international delegates.

To stimulate community involvement in human genetics, the South African Inherited Disorders Association (SAIDA) was started in Johannesburg in 1973 and Professor Jenkins was elected the Honorary Secretary. The aims of SAIDA were to increase awareness of genetic disorders, educate both the lay public and the medical profession on inherited diseases and the services available to deal with and prevent them, and support research. The Association also initiated and assisted in the development of genetic support groups and provided training to support parents. The Philip von Wielligh Trust was initiated through a generous donation to SAIDA and funded the visits of 17 eminent medical geneticists from abroad, who lectured and consulted with members of the local human genetics departments over a 20-year period. SAIDA also supported research by funding local human geneticists to attend and present their research at national and international conferences. To date SAIDA has about 25 affiliated active groups, dealing with both common conditions, such as Down syndrome, and rarer conditions, such as Williams syndrome.

\section{The future}

Over 20 years ago Professor Jenkins posed the question: 'Will medical genetics have any role to play in the envisaged democratic, non-racial post-apartheid society??.[2] In answer, he stated that with an emphasis on primary health and preventive medicine the infant mortality rate would decline (because children would no longer be exposed to infectious diseases) and demand for genetic services would increase (because congenital and genetic disorders would become more prominent). $\mathrm{He}$ added that these services would be developed only if university medical schools provided the necessary under- and postgraduate training in medical genetics. In the years since these remarks were made the academic centres have provided the necessary training, but the $\mathrm{DoH}$, at national and provincial levels, has not provided the required posts. This has resulted in training being reduced, to the detriment of future staffing needs, and there are currently serious staff shortages, so that services have had to be reduced.

Initially, in line with the Policy Guidelines for the Management and Prevention of Genetic Disorders, Birth Defects and Disabilities of the DoH ${ }^{[26]}$ the NHLS saw fit to provide posts for genetic counsellors and medical geneticists, but since then it has partially withdrawn funding for the programme. At present vacated posts are frozen, suitably qualified graduates are not employed and intern posts are not provided, so the country is losing the benefits of having trained professionals. Although some specialist training posts were provided in 2009, there are currently no posts for these newly qualified specialists in Johannesburg or elsewhere in the country, so there is a risk of losing these specialists too (in addition no new registrar posts are being offered). Similarly, sufficient numbers of medical scientists and medical technologists are not being trained or employed, the ageing laboratory equipment is not being maintained, and there is limited investment in new technology and equipment. As a result, the increasing demand for genetic testing cannot be met. This situation means that although South Africa has the potential, expertise and skills to provide an excellent genetic service, it is not being permitted to develop. With less than one-tenth of the required manpower for the population of over 50 million people, only a very limited (and daily becoming more limited) service can be provided.

\section{Conclusion}

As is apparent above, Emeritus Professor Jenkins has made an enormous contribution to the development of the field of human 
genetics in South Africa. However, as he has stated, 'If genetic services are to expand to meet the needs of the population a great deal of careful planning will be necessary. ${ }^{[2]}$ It is time to call for this expansion now, while the highly specialised skills required are still available, and while the country is facing the fact that $2-3 \%$ of its infants are being born with congenital malformations ${ }^{[29]}$ and $10 \%$ of its population is affected with a genetic disorder.

Acknowledgements. The assistance of the colleagues in the Division who read and commented constructively and helpfully on this manuscript is acknowledged.

1. Tjio JH, Levan A. The chromosome number of man. Hereditas 1956;42(1-2):1-6. [http://dx.doi. org/10.1111/j.1401-5223.1956.tb03010.x

2. Jenkins T Medical genetics in South Africa. I Med Genet 1990:27(12):760-779. [http://dx.doi. org/10.1136/jmg.27.12.760]

3. Beighton P, Fieggen K, Wonkam A, Ramesar R, Greenberg J. The University of Cape Town's contributions to medical genetics in Africa - from the past into the future. S Afr Med J 2012;102(6):446-447.

4. May PA, Gossage JP, Marais A-S, et al. Maternal risk factors for fetal alcohol syndrome and partial fetal alcohol syndrome in South Africa: A third study. Alcohol Clin Exp Res 2008;32(5):738-753. [http:// dx.doi.org/10.1111/j.1530-0277.2008.00634.x]

5. World Health Organization. Birth Defects. Report by the Secretariat EB125/7. Geneva: WHO, May 2009. 6. Gregersen N, Lampret J, Lane AB, Christianson AL. The greater Sekhukhune-Capability outreach project. J Community Genet 2013;4(3):335-341. [http://dx.doi.org/10.1007/s12687-013-0149-x]

7. Kromberg JGR, Sizer EB, Christianson AL. Genetic services and testing in South Africa. J Community Genet 2013;4(3):413-423. [http://dx.doi.org/10.1007/s12687-012-0101-5]

8. Jenkins T, Kromberg JGR. Prenatal diagnosis and selective abortion. S Afr Med J 1976;50:2091-2095,

9. Kromberg JGR, Bernstein R, Jenkins T, Bernstein J, Goudie E, Sneider P. Two years of mid-trimester amniocentesis in Johannesburg. S Afr Med J 1980;57:1031-1039.
am

10. Jenkins T, Lane AB, Kromberg JGR. Tay Sachs disease: Screening and prevention in South Africa. S Afr Med J 1977; $51: 95-98$.

11. Ramsay M, Thomson JA, Jenkins T. Antenatal diagnosis of sickle cell anaemia by means of DNA restriction analysis. S Afr Med J 1984;66:7-10.

12. Kromberg JGR, Bernstein R, Jacobson M, Rosendorff J, Jenkins T. A decade of mid-trimester amniocentesis in Johannesburg: Prenatal diagnosis, problems and counselling. S Afr Med J 1989;76:344-349
13. Jenkins T, Wilton E, Bernstein R, Nurse GT. The genetic counselling clinic at a children's hospital. S Afr Med J 1973;47:1834-1838

4. Kromberg JGR, Berkowitz DE. Managing genetic disorders. South African Family Practice 1986;7(9):279-285.

15. Carter CO, Fraser Roberts JA, Evans KA, Buck AR. Genetic clinic: A follow up. Lancet 1971:297(7693):281-285. [http://dx.doi.org/10.1016/S0140-6736(71)91016-6]

16. Kromberg JGR, Wessels T-M, Krause A. Roles of genetic counsellors in South Africa. J Genet Counsel (in press). [http://dx.doi.org/10.1007/s 10897-013-9606-2]

17. Kromberg JGR, Jenkins T. Marketing and providing an outreach genetic counselling service in southern Africa: Experience with 40 families in a new clinic. Proceedings of the 8th Annual Conference, National Society of Genetic Counsellors, New Orleans, 9-10 October 1988: 86A.

18. Kromberg J, Jenkins T. Cultural influences on the perception of genetic disorders in the black population of Southern Africa. In: Clark A, Parsons E, eds. Culture Kinship and Genes. London: Macmillan, 1997:145-157.

9. World Health Organization. Control of Genetic Diseases. Report of the Secretariat. 2005. https//apps. who.int/gb/ebwha/pdf_files/EB116/B116_3/en.pdf (accessed 1 May 2013).

20. Weatherall DJ. Hemoglobinopathies world wide: Present and future. Curr Mol Med 2008;8(7):592-599. [http://dx.doi.org/10.2174/156652408786241375]

21. World Health Organization. Community Approaches to the Control of Hereditary Disorders. Repor of WHO Advisory Group. Geneva: WHO, 1985 (document HMG/WG./85.10).

22. Kromberg JGR, Jenkins T. Genetic services in South Africa and common ethical issues related to genetic information. Specialist Medicine 1997:May:55-59.

23. Kromberg JGR, Jenkins T. Ethical, legal and sociocultural issues and genetic services in Souther Africa. In: Kumar D, ed. Genomics and Health in the Developing World. New York: Oxford University Press, 2012:585-598.

24. South African National Department of Health. Diagnostic Genetic Tests. 2007. Pretoria: NDoH, 2007. 25. Op’t Hof J. Genetic Services for Congenital and Hereditary Disorders. Pretoria: Eng Enterprises, 1985 26. South African National Department of Health. Policy Guidelines for the Management and Prevention of Genetic Disorders and Birth Defects and Disabilities. Pretoria: $\mathrm{NDoH}, 2001$.

27. Wertz DC, Fletcher JC, Berg K, Boulyjenkov V. Guidelines on Ethical Issues in Medical Genetics and the Provision of Genetic Services. World Health Organization Hereditary Diseases Program. Geneva WHO, 1995.

28. Greenberg J, Kromberg J, Loggenberg K, Wessels T-M. Genetic counselling in South Africa. In Kumar D, ed. Genomics and Health in the Developing World. New York: Oxford University Press, 2012:531-546.

29. Harper PS. Practical Genetic Counselling. 7th ed. London: Hodder Arnold, 2010. 